\title{
The Art of Spatial Flexion in Ancient Indian Sculpture Fabrication
}

\section{Chatterjee $S^{*}$}

Assistant Professor, Indian Information of Information Technology, Design and Manufacturing, India

*Corresponding author: Dr. Chatterjee Shekhar, Indian Information of Information Technology, Design and Manufacturing, Jabalpur, India, Tel: 9425150936; Email: schatterjee1971@gamil.com

\section{Review article}

Volume 1 Issue 3

Received Date: November 08, 2017

Published Date: November 17, 2017

DOI: $10.23880 /$ eoij-16000122

\section{Abstract}

The ancient sculptural tradition of INDIA has a significant characteristic. The images, whether they are in seated, standing or reclining postures, are invariably composed in a manner that reflects the grace of dance movements. Dance forms of this country express emotions in a lucid, richly flavored, aesthetically pleasing manner which lingers on in the heart of the observer. Dance communicates various feelings by the way of changing expressions on the face; flexions and posture of the body like bending curving and supplicating; and lastly through the gesture of the hands. The shilpi-rishis (Master sculptor), perceiving the sensitivity and richness of the expressions of dance, have absorbed this methodology of communication into the sculptural forms. As a result, the sculptural tradition has become invested with dynamism and vigour. The sculptures thus augmented with dance forms evoke an aesthetic response of a very high order. The flexions of arms and legs, and the arching of the body represented through very difficult method in stone sculptures. The stretching and extending of limbs has to be much more subtle and held closer to the main body (this is the constraint of the material itself), and yet evoke a response in the observer. The grammar of the flexions in dance takes on a different meaning and connation in the eyes of shilpī (Artist). The main divisions of the grammar are bhangaor body flexions and curves, āsana or postures and mudra or gestures.

Keywords: Spatial Flexion; Methodology of communication; Visual Culture; Postures and gestures; Art of Sculpture; Art of Fabrication

\section{Introduction}

India occupies an exalted position in the realm of art of the ancient world. If the Greeks excelled in the portrayal of the physical charm of the human body, the Egyptians in the grandeur of their pyramids and the Chinese in the beauty of their landscapes, the Indians were unsurpassed in transmitting the spiritual contents into their plastic forms embodying the high ideals and the common beliefs of the people. The Indian artists visualized the qualities of various gods and goddesses as mentioned in their scriptures and infused these qualities into their images whose proportions they based on the idealized figures of man and woman. Indian art is deeply rooted in religion and it conduces to fulfilling the ultimate aim of life, moksha or release from the cycle of birth and death. There were two qualities about which the Indian artists cared more than about 


\section{Ergonomics International Journal}

anything else, namely, a feeling for volume and vivid representation, even at the risk of sacrificing, at times, anatomical truth or perspective. Senses of narrative a taste for decoration, keenness of observations are clearly brought out in each sculpture.

Indian art is a wholesome, youthful and delicate art, a blend of symbolism and reality, spirituality and sensuality. Indian art may well be said to bear in itself the greatest lesson an exemplary continuity from prehistoric times to the present age, together with an exceptional coherence. We said earlier that Indian art was inspired by religion and birth place of three of the world's great religions Hinduism, Buddhism and Jainism and these three faiths have inspired most of our Indian art. I use the word 'most' purposely for the simple reason that not all Indian art is religious. The Indian artist was a man of this universe, he lived here, looked around himself, saw the joys and sorrows of the life and reproduced them in whatever medium he happened to be working in at a given time; clay, wood, paper, metal or stone. The creation of art by the Indian artists are not realistic representations in the sense we understand the term on Greek or Roman Art depicted but they are imagined and are idealized to its extreme.

\section{Measurement of body in flexions and curves}

The curves and flexions of the body are called bhanga. This can be classified into three types: ābanga, samabhanga, atibhanga. Since the flexions of the body are in three parts in all of these, each is also known as tribhanga.

When a figure is erect, without any bend or displacement of weight away from the center of gravity or bodily plumb line, and the arms and legs are placed in a stable position with a direct gaze, the sculptural image is called samapādasthānakam (stable erect posture in equilibrium). When such an image is represented in an arched, curved or flexed posture, its height is found to be less than that of the erect figure $[2,3]$.

The samapādasthānakamor erect posture of an image denotes the balanced stable position of a measuring balance in equilibrium, which does not sway or shift. When the image is represented in a ābhanga posture, it portrays the serenity and gentleness. An image in samabhanga posture characterizes sensuousness (sringāra) and passion (rajasa). Atibhanga signifies the aggression and pride of vīra (valour).

These are the three bhanga postures that are largely used for fashioning images meant for worship. Their faces should be represented with a serene expression, the eyes compassionate and the lips parted in a benevolent smile. Since the basis for images created for worship is their gracious ability to cleanse and purify the soul of the devotee, these principles should be adhered to. There are various ways in which flexions or bhanga in the figure can be determined. The plumb line or central line is that which passes from the head downwards, through the forehead, nose, chin, chest, navel, genitals, between the thighs and feet in an erect figure. This is called the madhyasūtram. This central plumb line is absolutely essential in creating equilibrium and stability in the erect figure. It is possible to determine the shift or curve of the various parts of the body only with reference to the central plumb line.

It is a very interesting and practical way of manipulating the female figures although they don't appear veered. They all create the natural movement of eyes all around. The eyes movement is controlled by the depiction of static and dynamic figures. The static figures are the architectural forms present in the monument and the dynamic forms are the movement of female forms in different gestures and postures. There is the combination of static and dynamic forms together creating a rhythm in our perceptual subconscious mind. So our conscious mind is not aware of this mechanism in our brain but the outcome is always very pleasing. The pleasure which has been experienced by the viewer is actually manipulated measurement of body in flexions and curves present in the sculptures. It is indeed a very interesting analytical approach of sculptural art in India tradition. This creative ethnic tradition strictly followed by Indian craftsmen generation after generation. Although their designs do not appear within the format only, the extreme improvisation of style and form application generated variation in their work. Different dynasties and their distinct style followed strictly the canons of Sthāpatya Kalā (Art of Fabrication) and Silpa Kalā (Art of Sculpture) although their style and quality was never compromised in fabrication. Minute cultural observations were the key points of variations in style and manner in Śilpa Kalā (Art of Sculpture). For this reason all the ancient monuments seem distinct. Analytical observation of body shift and flexions from the central plumb line in Apsarā Figures 1-5. 

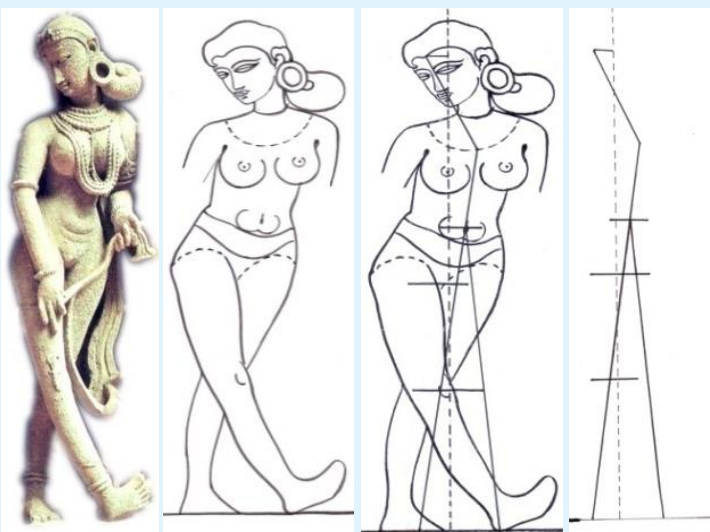

The shift:

Forehead from center $1 \mathrm{~cm}$

Naval on the left side $1 \mathrm{~cm}$

Right knee

$0.5 \mathrm{~cm}$

Right heels on left side $\quad 2 \mathrm{~cm}$

Figure 1: The central plumb line passes through side mid of the left eye, center of the right breast, off-center of naval, genitals, mid of the left thigh and right knee.

The visual balance is created by twisting the body in opposite direction. The face is turned on right hand side and the right foot is extended on left hand side. So the variance is applied on upper and lower part of the body by extending their position on opposite direction from the central plumb line.
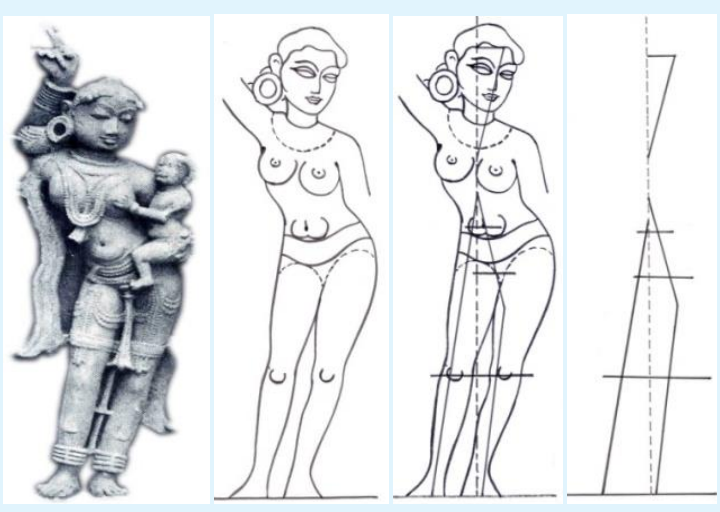

The shift:

Forehead from centre

$1.2 \mathrm{~cm}$

Naval on the left side

$0.5 \mathrm{~cm}$

Genitals on left side

$1 \mathrm{~cm}$

Left knee on the left side

$1 \mathrm{~cm}$

Right knee on the right side

$1.2 \mathrm{~cm}$

Right toes on right side

$2.5 \mathrm{~cm}$

Figure 2: The central plumb line passes through side corner of the right eye, slightly off-center of collar bone, mid of the right thigh and left heel.

The visual balance is created by shifting the body weight in opposite direction. The face is turned on left hand side and the right feet extended on right hand side. Here the body weight is on left foot so the waist line extended towards left but left heel takes the body weight and attached to central plumb line. So the variance is applied on upper and lower part of the body by extending their position from the central plumb line towards opposite direction.

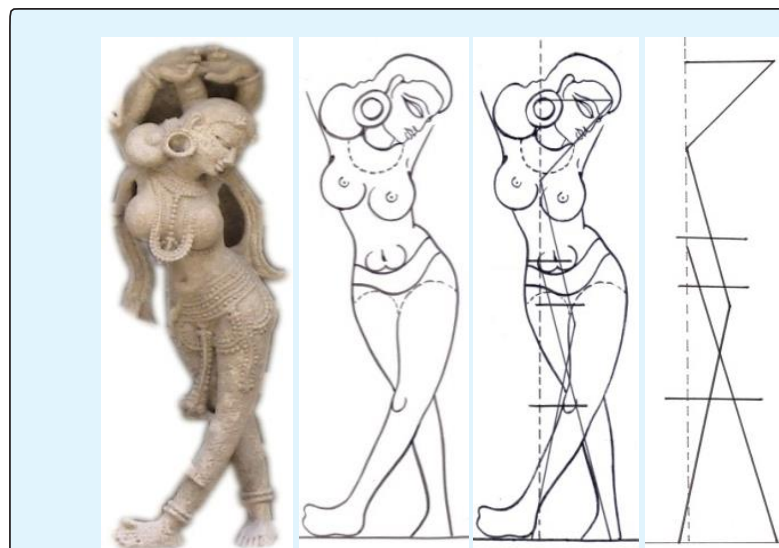

The shift:

Forehead from center $\quad 3.5 \mathrm{~cm}$

Naval on the left side $\quad 1 \mathrm{~cm}$

Genitals on left side $\quad 1.5 \mathrm{~cm}$

Right knee and left knee $2 \mathrm{~cm}$

Right foot on left side $\quad 3.5 \mathrm{~cm}$

Figure 3: The central plumb line passes through side mid of the right ear, off-center of the right collar bone, off-center of naval, mid of the right thigh and left foot.

The visual balance is created by twisting the body in opposite direction. The face is turned on left hand side and the left foot is extended on right hand side. The body is balancing on the right foot. So the variance is applied on upper and lower part of the body by extending their position on opposite direction from the central plumb line.

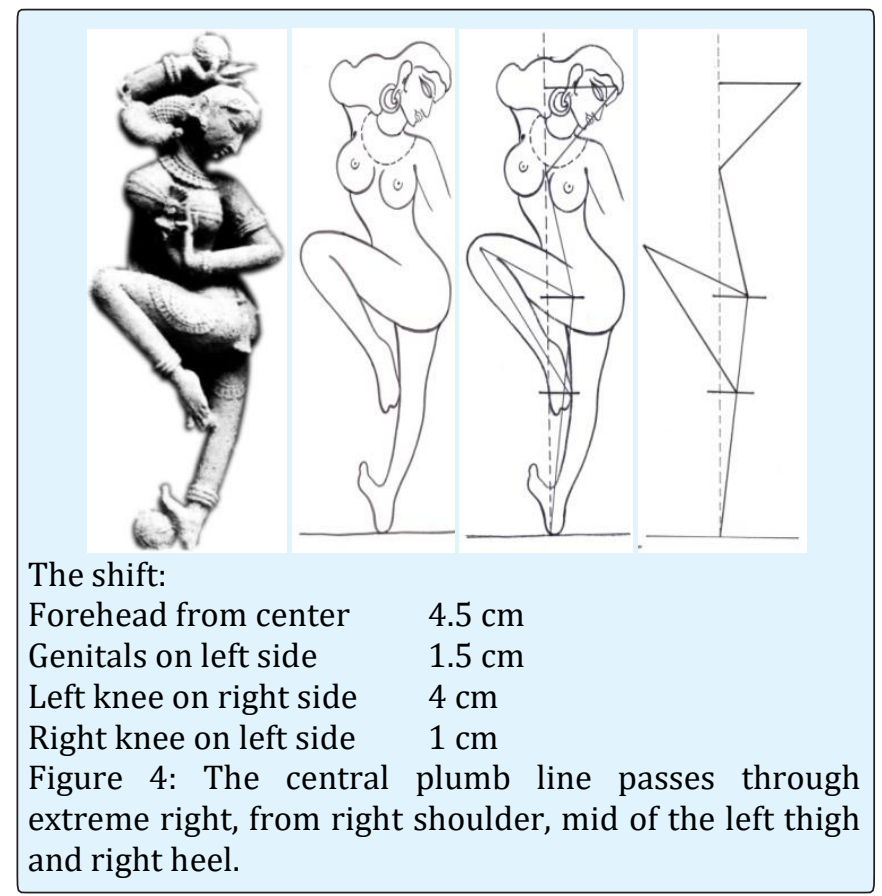


The visual balance is created by shifting the body weight as well as twisting the body movement in opposite direction. The face is turned on left hand side and the left foot extended on right hand side. Here the body weight is on right foot and the hip is extended towards left but left leg makes the dynamic body movement. So the variance is applied on upper and lower part of the body by extending their position from the central plumb line towards opposite direction with a proportion [4].

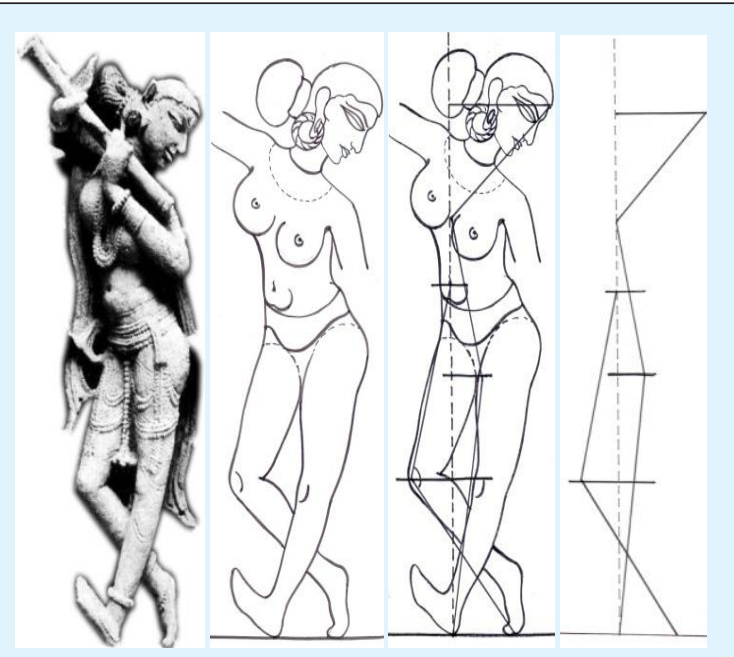

The shift:

Forehead from centre $\quad 5 \mathrm{~cm}$

Genitals on left side $\quad 1.5 \mathrm{~cm}$

Left knee on left side $\quad 1 \mathrm{~cm}$

Right knee on right side $2 \mathrm{~cm}$

Right toes on left side $3 \mathrm{~cm}$

Figure 5: The central plumb line passes through extreme right, from right shoulder, from naval, mid of the right thigh and right heel.

The visual balance is created by shifting the body weight as well as twisting the body movement in opposite direction. The face is turned on left hand side and the left foot's lifted movement towards right hand side. Here the body weight is on left foot and the hip is extended towards left but left leg is on central plumb line. The right knee is extended towards right side but the toe is towards left. Both the legs are intersecting each other. So the variance is applied on upper and lower part of the body by extending their position from the central plumb line towards opposite direction with a proportion.

The line drawing helps to understand the Analytical observation of Spatial Flexio in the sculptures.

a. The central plumb line passes through the middle of the two breasts; exception is the figure number 3.

b. The Apsara sculptures are shown maximum their head turned towards left.

c. Body gesture is realistically balanced by the principle of shifting the body weight on one leg and the waist line of the same leg is uplifted and the shoulder is bended down. This is the natural principle of human body.

d. The movement of the free leg actually balanced the composition visually although many times, but it is the exaggerated posture but seems realistic in composition.

e. The lower body part seems larger than the upper part but centre point of the Apsara sculptures is just above the genitals.

f. The upper part of the body looks heavy because of heavy breasts and their front projection.

g. The turning of head is having the relation of the movement of knee or opposite knee in reverse direction proportionately to balance the composition.

h. The movement of all the joints like neck, waist, knee and feet are overstated by the master craftsmen to represent the various ways in which flexions or bhanga can be determined.

i. The hands movements are not shown in the sketch of the figures to avoid their activity, here the movements of the entire body without hands are observed particularly in Spatial Flexion.

j. They are all seven heads figures. The face is considered to be one Tãlam in rhythmic measurement.

In the field of sculptural measurement, particularly in connection with divine images, there is a very special scale known as tālamānam or rhythmic measure. The adoption of the talamanam not only ensures the symmetrical beauty and artistic grace of the images but also imparts unique spiritual meaning and symbolism to them. The grammar of measurement has been evolved through the formulation of an orderly system with regard to the consonant rhythmic relationship between the parts of the body. The fundamental unit from which the rhythm of the various bodily parts can be interrelated is the length of the face. This facial length which is the basic unit is an extremely significant part of the sculptural tradition.

The head forms an important part of the whole body. In this, the long portion between the forehead and the chin is called the face. The length of the face or mukham (face) is equal to the distance between the middle finger and thumb of the extended hand (span of the hand).The length of the palm, from the wrist to the tip of the middle finger is also equal to the facial length. This length of hand, standing for the length of the face, is adopted as the basic unit in sculptural tradition.

Mayan, the most ancient authority on fine arts, has given a better definition of the tāla measure. According to him, tāla is a foot measure. It is very significant that the word tāla is used in the field of dance as well, where it denotes the rhythm of footwork. 
It may be noted here that, in the artistic traditions, tāla or time-measure and distance or space-measure are viewed on the same plane. In the field of music, the rhythmic time-measure called tāla ensures the order and sweetness of a melody. Similarly, tāla in the sculptural field ensures the order and beauty of an image. In architecture and poetry, tāla is replaced by the word pāda, which also means foot. One will recognize, thus, the supreme role of rhythm in the world of fine arts [1].

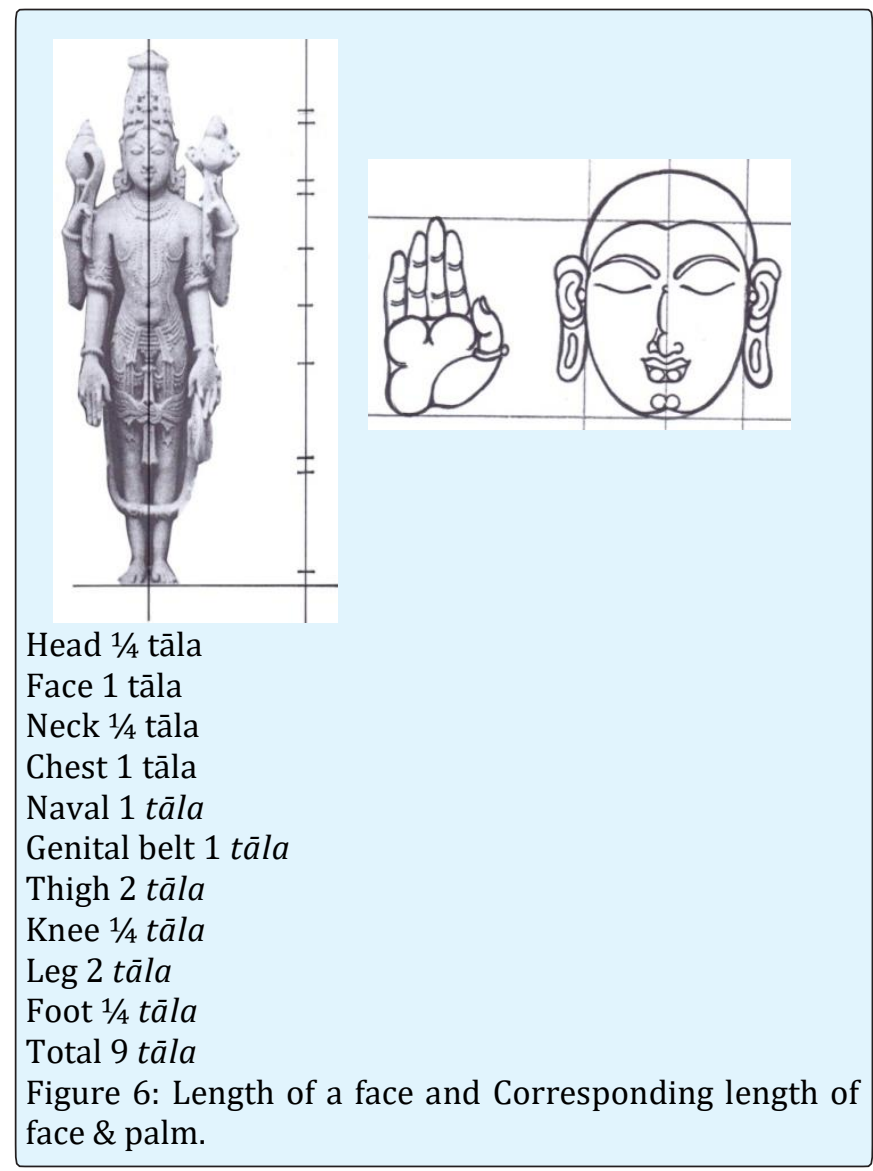

This is a very ancient linear measure which speaks of the bodily form of the image as navamukham in height (navamukham $=$ nine faces).

The mukham measure is taken as 12 viral. An elaborate scale has been devised by breaking up the total form into related sub-parts. This measure is thus a relative measure. We can see the relationship of the face to the chest as one mukham length, thigh and leg as 2, genital belt as 1 , the knee, neck and feet as $1 / 4$ of the face. The shilpa texts call this mukham measure as tāla. Hence, the same table will read as follows:

This is called navatāla in the tālamānam or tāla scale. While the tāla measure can be used to set out the dimensions of larger parts of the body, smaller aspects like eyes, ears, nose, mouth, fingers, etc., cannot be measured in this system. Therefore, certain minute divisions have been designed.

The navatāla measure is not the only type of measure. There are many other rhythmic measures which have been adopted to represent a variety of forms, ideologies and qualities. To express all these, many kinds of tālamānam have been calculated to give tangible forms to artistic vision as well as to represent various physical forms such as male, female, children, dwarves, demons, etc. Generally, sacred images are called padtmam and images of devotees (adiyavar) are called thirumeni.

With navatālaas the middle scale, one larger is called daśatāla (daśa = 10), and one smaller is ashțatāla (ashta $=8$ ). These 3 are the most important of the tāla measures. Further, in order, saptatāla (7), shattāla (6), panchatāla (5), chatustāla (4), tritāla (3), dwitāla (2) and ekatāla (1) make up ten tāla in all. The texts describe the saptatālaimage as vāmana, the ashtatālaone as mānusha, and that of navatāla as deivika (god or goddess). Child images are made in pañchatāla, and the images of youthful gods in shattāla. These classifications are special for divine images only.

\section{Artistic Representation of the Various Parts of the Body}

The image in sculptural tradition, though outwardly representing the human body, is not a direct copy of the human figure. The forms of nature that resemble the parts of the human body are copied artistically. The sculptor shows his skill in absorbing the inherent form of the natural model and depicting it in the bodily aspect of the image. All the specific details of the original need not be faithfully rendered; its form should only be simulated the resemblances to natural forms that have been used in fashioning sacred images.

Face: The face is divided into 3 parts, the forehead, the nose and the remaining part up to the chin. In general, the width and height of the face are taken as 1 tola. But there are several types of face forms which have been specified-the oval/round shape, mango shape, egg shape, or seasame seed shape (Figure 7-10).

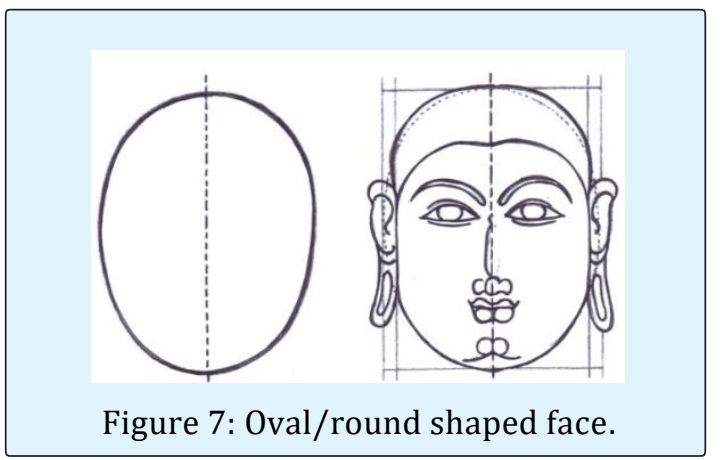




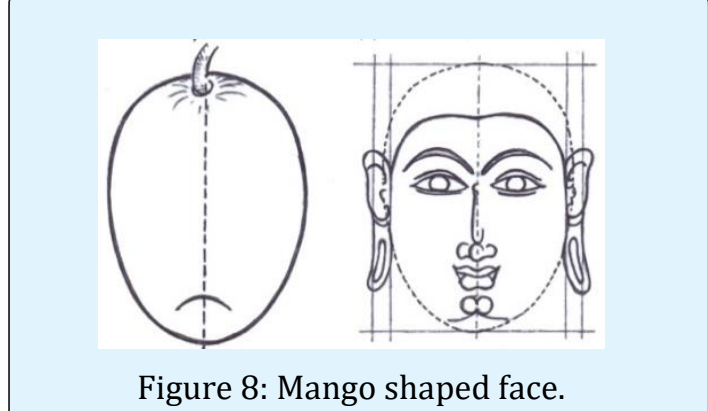

Figure 8: Mango shaped face.
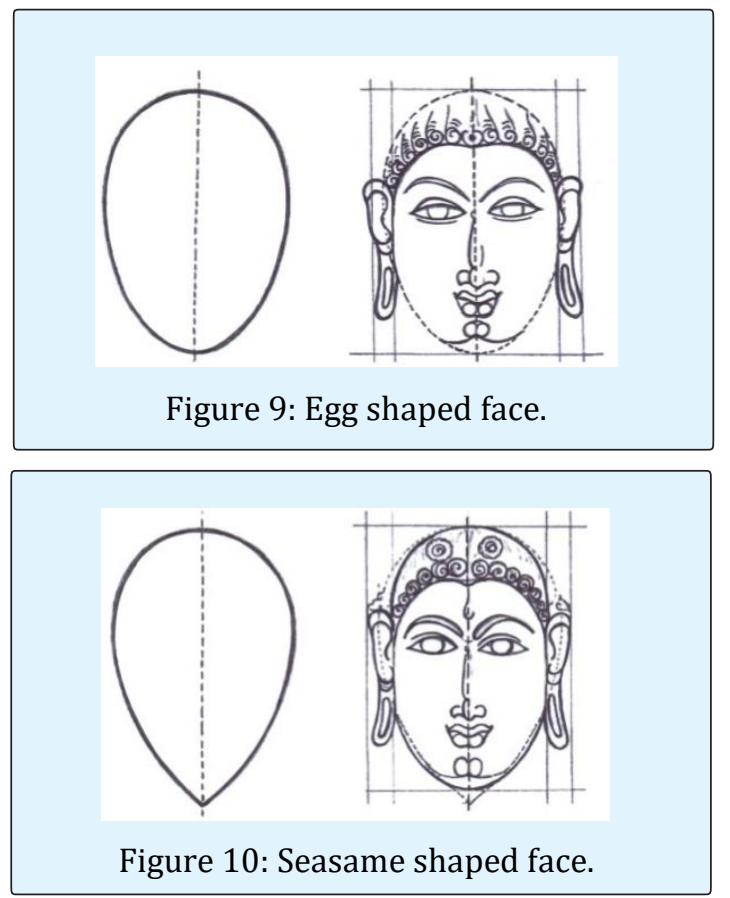

The egg shape and seasame shape are considered most suitable for female faces while the others are suitable for male faces. The top of the head should be shaped like an umbrella. The forehead should be shaped like a half-moon and the hair-line like crescent moon on the second day. The tip of the nose should be shaped like a seasame flower. The nostrils should be shaped like bean seed. The center of the eyebrows are curled when the artists wants to show distaste, irritation, indignation, or surprise. The base is curled to express an intent gaze or disgust. The eyebrows in a clear bow shape indicate tranquility (Figures 10-12).

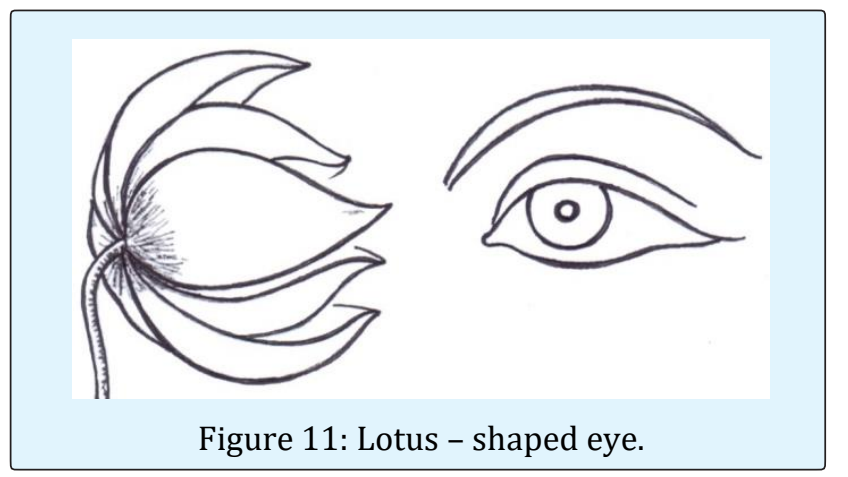

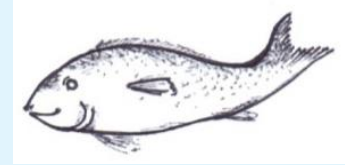

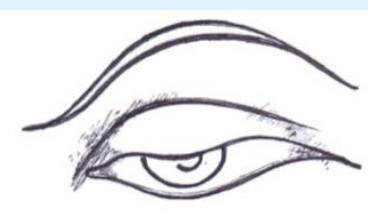

Figure 12: Fish - shaped eye.

- The eye can be shaped like a fish, or lotus petal, or lily, or water iris. The outer edge of the eye should be reddish in color; the iris should be black, and the rest of the eye white.

- The ear should look like a conch, and the hanging earlobe should resemble the handle of a pair of scissors.

- The lips should be like a red berry in shape and color.

- The neck should be rounded like a conch, with two fine lines on it.

- The upper arm is equal to the neck in its width, and should be rounded with the flesh well defined.

- The arm begins very wide, narrows a little at elbow level, and tapers to the wrist. The shape of the arm resembles the trunk of an elephant. The arm of a female image is like a bamboo stalk or like a palmshoot.

- In each finger, the nails should be fixed to the upper half of the top node. They should be moon-shaped.

- The chest and naval of a male body resembles the face of a bull.

- The waist of a female resembles a vajra implement or a drum (damru).

- The female torso also brings to mind the face of a lion with it spherical breasts, the three lines on the abdomen, and deep indentation below the naval.

- The naval should be clockwise spiral, with its outer edge graded like an opened lotus flower.

- The heel of the foot should resemble the shell of a tortoise. The feet should be represented as firmly, evenly placed, the toe nails like shells.

The remaining measures have to be adopted in proportion to these measurements. The arms should be slender and should narrow down in a very graceful manner. The thighs and legs should be like the trunk of an elephant, the abdomen should be like a peepul leaf, and the genital smoothly defined without any projections. The breasts should be rounded, and shaped according to the structure and age of the represented image. Since the images (every aspect of whose forms are aesthetically rendered in this manner) emerge from the soul or atman of the artist; they evoke and awaken the spirit of the viewer. This is why these images are considered sacred and have been sources of inspiration and devotion (Figures 1316). 


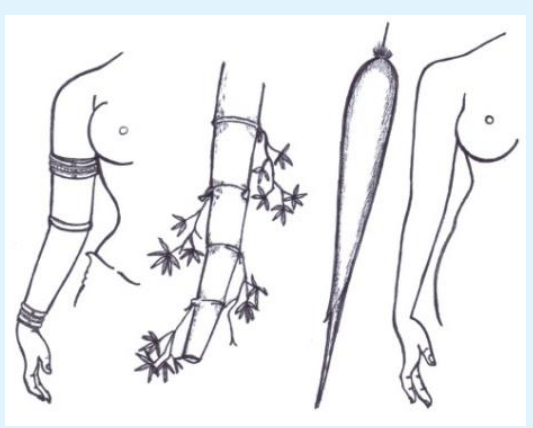

Figure 13: Arm shaped as bamboo \& palm-shoot.

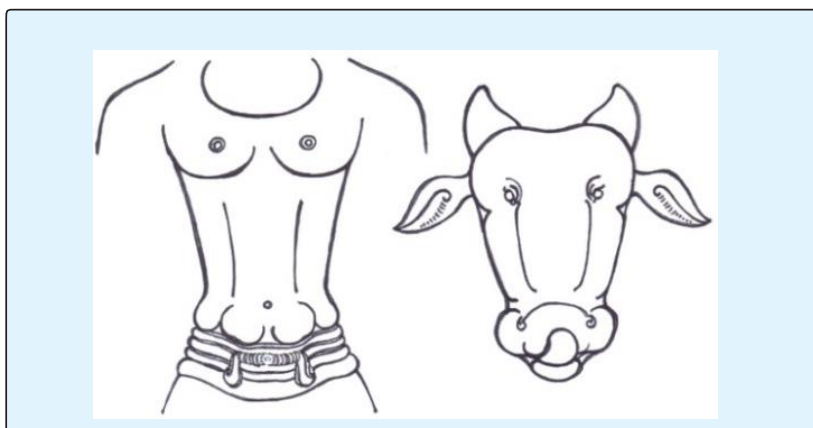

Figure 14: Male torso shaped like head of a bull.
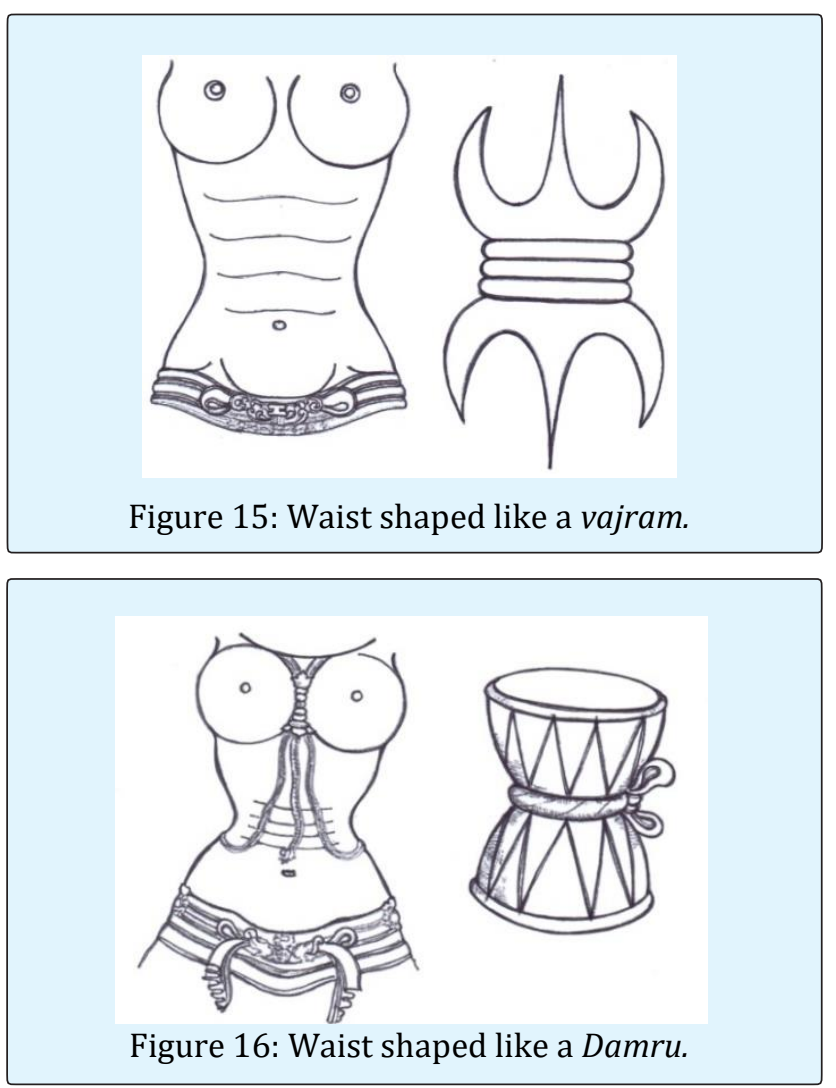

An umbrella-shaped head of the divine image would lead to rich harvests and great income. A beautiful forehead, with well-defined eyebrows, ensures a stable and secure income. A well-proportioned image would bring about happiness to the community. A gracefully rounded neck ensures success in action. The magic body which resembles the torso of a lion would bestow progress and success. Arms resembling the trunk of an elephant would satisfy all desires. An attractive abdomen would lead to rich harvests and long-lasting wealth. Beautiful thighs like the stem of a banana tree would ensure fertile crops, attractive ankles would protect the growth of villages, and pretty feet would foster learning and add to the moral values of the community.

When the magic measurements are less than those that have been specified, the community would experience famine and internal conflict. If the image is without a body or without a nose, then the worshipper would have a hunched back or be afflicted with a disease. If the image is cross-eyed, with the eyes looking left, the livestock in the community would be destroyed; if the gaze is upward, the wealth would be eroded. Images which are too small, with downcast eyes, should be removed altogether. If the abdomen of the image is sagging, crops would be destroyed. An image with thin thighs portends threats to the chastity of women. In the same way, it is not considered good for the nose, eyes and fingers to be too long or the head, ears and nose to be too small, the elbows, nails and stomach to be swollen, arms and feet to be twisted, neck, mouth and shoulders narrow. Hence, it is of utmost importance that shilpis create and devotees worship perfect images.

\section{Conclusion}

None had actually seen the gods like Rāma, Krishṇa, Viṣnu and Śiva, etc., but according to their description in the scriptures the Indian artists visualized them as shown generally standing erect, signifying mental power, physical and spiritual equilibrium. In form, the males are virile beings broad shouldered, deep chest and narrow hipped. The females are precisely contrary to the males narrow shouldered, having full and blossom breasts, and attenuated waist and broad hips. The females according to the Indian artists represent Mãtri or the mother. Indian art is a treasure house of ancient contemporary life, its faiths and beliefs, customs and manners. It is considered by some to be the function or purpose of art of any age to mirror contemporary society, its customs, manners, habits, modes of dress and ornamentation etc [5-7].

Culture is most complicated word; the first important assertion is that no culture has appeared or developed without a religion: according to the point of view of the observer, the culture will appear to be the product of the religion, or the religion the product of the culture. Culture is the one thing that we cannot deliberately aim at. It is the product of a variety of more or less harmonious activities, each pursued for its own sake. 


\section{Ergonomics International Journal}

Culture may even be described simply as that which makes life worth living. Culture is something more comprehensive than religion; that the latter is no more than a necessary element, supplying ethical formation and some emotional color to Culture which is the ultimate value. We may go further and ask whether what we call the culture and what we call the religion of a people are not different aspects of the same thing: the culture being, essentially, the incarnation of the religion of the people. To reflect that from one point of view religion is culture, and from another point of view culture is religion.

Culture is something to which we can afford to remain indifferent. Aesthetic sensibility must be extended into spiritual perception, and spiritual perception must be extended into aesthetic sensibility and disciplined taste before we are qualified to pass judgment upon decadence or diabolism or nihilism in art. To understand the culture is to understand the people, and this means an imaginative understanding. Such understanding can never be complete: either it is abstract-or the essence escapes-or else it is lived. Religion and culture are aspects of one unity, and that they are two different and contrasted things. No religion can be understood from the outside-even for the sociological purposes.

Formation of a religion is also the formation of a culture. A religion as a whole way of life of a people, from birth to the grave, from morning to night and even in sleep, and that way of life is also its culture. The system of cultural value accommodated all sorts of Indigenous cultural activity in the ornamentation of the monument. Without the attraction they could not affect each other, and without the repulsion they could not survive as distinct cultures; one would absorb the other, or both would be focused into one culture. Jewellery, metal work and precious stones, worn mainly by women, reflect light particularly well and so act as magnets for sight. Gleams and glitter enable the wearer to be a centre of emanation, to extend the self beyond bodily limits, and to attract the gazes of others.

The abstract ideas represented in terms of animals or people as known as personification. The gods and goddesses of classical myths were endowed with human qualities, and female figures have repeatedly been used to personify such concepts as liberty, peace, beauty, love, adornment, rituals, dance, dawn, nation and the muse of painting and sculpture. In societies dominated by religious ideologies, control of the population's behavior was facilitated by the idea that God was watching and judging everyone all the time. This visual effect reinforces the omniscience of God's gaze.
The art of painting and sculpture developed particular visual and cognitive skills and facilitated their scope of appreciation. The eye was a central means of self-representation and visual experience a central mode of self-consciousness. Artists were likely to flourish in a society to develop visual culture. Their analysis focuses even upon pleasures supplied by Visual Culture [8]. Every artifact is the result of multiple determinants or factors - economic, political, cultural, institutional, technological, human need, creative will or desire, etc. Visual culture focuses the basic facts about the physiognomy of the eyes and the psychology of visual perception, not only because such knowledge is pertinent to the subject in general, but also because many artists have acquired and made use of such knowledge.

Our knowledge of reality comes from many acts of perception which we compare and subject to logical analysis. Viewers are not pairs of eye - they have minds, bodies, genders, personalities and histories. The fact that we perceive one world rather than five (corresponding to each of the five senses) suggests that inside the brain/mind visual information from the eyes merges with information arriving from the other senses, and with existing memories and knowledge, so that a synthesis occurs. It is through our senses that we interact with and learn about the world.

Most designed works; they are new inventions, addition to nature. Because drawing, painting, sculpture appeal to sense of touch as well as sense of sight. They need not limit themselves to what already exists, they can present imaginative vision of fictional worlds and creatures - such as fairies and aliens from outer space which can still have a compelling reality effect. I would like to quote the remarked by Paul Klee: 'Art does not reproduce the visible; rather it makes visible'.

\section{References}

1. Sthapati VG (2002) Indian Sculpture and Iconography, Form \& Measurement. Sri Arobindo Society Pondichery in association with Maping Publishing, Ahmedabad.

2. Swami Chidatmanjee (2009) Art Forms of India. Anmol Publication Pvt. Ltd, New Delhi.

3. Sompura KF (1969) The Structural Temples of Gujarat. Ahmedabad.

4. Roy Brajdeo Prasad (1992) Techniques of Making Stone Imges in Ancient India. Motilal Banarasidas Pvt Ltd, Delhi. 
Ergonomics International Journal

5. Natalia Lidova (1996) Drama and Ritual of Early Hinduism. Motilal Banarasidas Private Limited, Delhi.

6. Deva Krishna (1995) Temples in India, Aryan Books International.
7. Shivaramamurty C (1993) The Art of India. In: Harry NA, Reissue.

8. John AW, Sarah Chaplin (1997) Visual Culture: An Introduction. Manchester University Press. 